\title{
Comparative Analysis of Angles and Movements Associated with Sporting Gestures in Road Cyclists
}

\author{
Gabriel P. da Silva ${ }^{1}$, Bruno Ferreira ${ }^{1}$, Geraldo C. da Silva Onety ${ }^{1}$, Edson D. Verri ${ }^{2}$, Selma Siéssere ${ }^{1}$, \\ Marisa Semprini ${ }^{1}$, Victor R. Nepomuceno ${ }^{3}$, Saulo Fabrin ${ }^{*}, 1,2$ and Simone C.H. Regalo ${ }^{1}$ \\ ${ }^{I}$ Department of Morphology, Physiology and Basic Pathology, Electromyography Laboratory, University of São Paulo - \\ USP, Ribeirão Preto - SP, Brazil \\ ${ }^{2}$ Claretiano University Center, Batatais, São Paulo, Brazil \\ ${ }^{3}$ Federal University Tocantins, Palmas, Brazil
}

\begin{abstract}
Objective: To compare the angles of both hemibodies and movements associated with sporting gestures in road cyclists.

Methods: Fifteen right-handed male road cyclists, with a mean age of $27 \pm 4.25$ years, participated in the study. Subjects who were younger than 18 years old or were previously diagnosed with posture impairment, motor disorders, and cognitive or mental deficits were excluded. Measurement procedures were performed using biophotogrammetry and kinemetry to analyze the angles and biomechanics of sporting gestures during the activities.

Results: Based on the results of biophotogrammetry, the angles measured showed symmetry among the participants. The kinematics analysis revealed that the trunk flexion did not show any significant differences between the angles when the sporting gestures were performed. When the triple maximum flexion of the lower limbs and the maximum extension of the lower limbs were analyzed, a statistical significance $(\mathrm{p}<0.05)$ between the angles in both sitting and standing positions was found. However, the results showed a direct association with the desired physiological movement, which did not affect the function.

Conclusion: The results showed that the biomechanics of the angles between both hemibodies and the sporting gestures in cyclists were not affected. This finding is directed in particular to the implementation and planning of training practices that will raise the awareness among cyclists of their bodies and the appropriate adjustments of the bicycle components.
\end{abstract}

Keywords: Biophotogrammetry, cycling, kinematics, posture, sporting gesture.

\section{INTRODUCTION}

Cycling is a sport that demands agility, good physical conditioning, muscular strength and flexibility. This sport may lead to postural changes due to constant and repetitive training in addition to a vicious stance during sports practice that typically consists of trunk flexion combined with rotation and load bearing [1]. The position of the body has significant influence on the activation of the lower limb muscles. When the trunk angle is altered, it changes the activation of all of the lower limb muscles and even those muscles that do not cross the hip joint [2]. Among the possible reasons for these changes in the activation of the lower limb muscles is the change in the trunk angle, which is related to differences in the activity of the mono and biarticular muscles or to the influence of muscle length, leading to global changes in the muscle recruitment patterns [3-6]. Savelberg, Van de Port and Willems (2003) observed that the changes in the trunk angle require "compensation" to

*Address correspondence to this author at the Department of Morphology, Physiology and Basic Pathology, Electromyography Laboratory, University of São Paulo - USP, Avenida do Café s/n, Ribeirão Preto - SP, Brazil; Tel: +55 16 3602-0182; E-mail: saulo.fabrin@gmail.com sustain the patterns of muscle activation that are required to prolong the workload. These "compensations" refer to shifts in the magnitude of activation of the lower limb muscles that maintain the force generated [2].

Pedaling is not a natural movement in the ergonomics of the human being, and as a result, some discrepancies in body positioning may cause cycling-related injuries. Therefore, the riding position involves the optimum setting of three points of contact with the bike: the pedals, the saddle and the handlebars. The weight distribution on these three points affects the location of the center of mass of the rider. An adequate and comfortable posture will allow the cyclist to maneuver the bike easily without shifting the center of gravity too far forward [7].

The combined bike and rider center of gravity depends on the height of the central movement from the ground and is considered a key factor to achieve a comfortable adjustment. A lower seat height makes for easier remounting, and a lower center of gravity increases stability. However, the position of the rider is a relevant factor because adopting certain positions and angles can help eliminate the etiological factors responsible for the repetitive 
stress injuries that have a direct influence on the efficiency of the cycling process [8]. Martins et al. (2007) reported that the lack of information on how to use a bike properly may cause cyclists to adopt a straining posture when cycling, particularly with excessive flexion or knee extension during pedaling [7].

Researchers have reported that it is possible to improve cycling performance via kinesiology by adjusting both the rider and the bike [9]. Biomechanical findings for the biophotogrammetric and kinemetric assessments allow studying the angles and gestures of the kinematic and linear movements, respectively, making it possible to obtain spatial measurements of the human body [10-12].

\section{OBJECTIVE}

The objective of this study was to perform a comparative analysis between the angles of both hemibodies and the movements associated with the sporting gestures in cyclists using biophotogrammetry and computerized kinematics analysis.

\section{METHODS}

\section{Sample}

Fifteen right-handed male road cycle athletes who had been competitors for over 5 years, with a mean age of $27 \pm$ 4.25 years, participated in the study. Subjects who were younger than 18 years old or were previously diagnosed with posture impairment, motor disorders, and cognitive or mental deficits were excluded. All of the individuals were duly informed regarding the conditions of this study and signed the informed consent. This research was approved by the Research Ethics Committee of the Claretiano University Center of Batatais, N. 91/2011 CEP.

\section{Development and Analysis of Computerized Biophoto- grammetry}

\section{Material}

The individuals were photographed using computerized biophotogrammetry. This evaluation was performed with the individuals wearing light clothes. To standardize the images, each subject was positioned on a three-dimensional leveling platform in front of a panel known as a simetrograph $(200 \times 100 \mathrm{~cm} \times 10 \mathrm{~cm})$. A wall-ground leveling criterion was maintained prior to positioning. An 8.5-megapixel Kodak p880 camera was positioned on a tripod with a 3-meter distance between the focal lenses of the camera and the central area of the individual's body. This distance was demarcated on the ground with masking tape. Another measure of standardization was the tripod height, which was set at $0.90 \mathrm{~cm}$.

\section{Procedures}

The images were obtained by a single observer without zoom and in three delimitation planes: anterior, lateral and posterior. The markers were positioned in the following body segments: the manubrium of the sternum, the acromion, the lateral epicondyle of the humerus, the styloid process of the radius, vertebra $\mathrm{C} 7$, the lower and upper angles of the scapula, and anterior superior iliac spine bilaterally, enabling an angle analysis of the shoulder alignment during elevation, scapula rotation, trunk and pelvic inclination in the right and left hemibodies.

Subsequently, the images were analyzed using the SAPo software (version $0.68,2007$ ), and the data were tabulated and submitted to statistical analysis using SPSS, version 21.0 (Chicago, IL, USA). The values obtained from the right and left hemibodies were compared using an independent t-test.

\section{Development and Analysis of Computerized Kinemetry}

\section{Material}

The biomechanics of the sporting gestures in cycling was assessed by computerized kinemetry using an 8.5-megapixel Kodak p880 camera that was positioned on a tripod (height set at $0.90 \mathrm{~cm}$ ) with a 3-meter distance between the focal lenses of the camera and the central area of the individual's body.

\section{Procedures}

The procedure was conducted with markers placed at the following landmarks: L4, inferior angle of the scapula, C7, anterior superior iliac spine, the fibular head and lateral malleolus bilaterally. A pen was used to mark the reference points for subsequent application of an adhesive paper. For the video data collection, the individuals were positioned on a Monaco bike (model R-Track) and were instructed to perform the activity in standing (orthostatic) and sitting positions. Data collection for each position lasted 10 seconds. Each video was analyzed in reference to the trunk flexion angle, triple maximum flexion of the lower limbs and maximum extension of the lower limbs. The relevant data were transferred to a computer using a firmware and an editor card opened in the Quintic Biomechanics 9.03v17 video analysis software, which captured the data in MPEG-4 format.

The video frames were cut or analyzed dynamically with reduced timeline speed. Data were tabulated and submitted to statistical analysis using SPSS, version 21.0 (Chicago, IL, USA). The values obtained from the right and left hemibodies were compared by an independent t-test. The angles of trunk flexion, triple maximum flexion of the lower limbs and maximum extension of the lower limbs were compared in both standing (orthostatic) and sitting positions.

\section{RESULTS AND DISCUSSION}

The position and the symmetry of the angles that comprise the complex interaction bike-rider system may affect the magnitude and direction of the force applied to the pedals and the pedaling technique, the neuromuscular strategy adopted, the economy of motion, the probability of injuries, the aerodynamic friction and, more directly, the sensation of comfort on the bike [13, 14]. Thus, it was possible to determine that the angle measurements obtained from the road racing cyclists using biophotogrammetry revealed no significant results when both right and left hemibodies were compared. Relevant angular changes that occur between the hemibodies have proved the asymmetries and consequent imbalances in muscle groups and in the center of gravity, which would most likely generate certain pathologies. Therefore, the statistical analysis found $\mathrm{p}>$ 0.05 , which suggests a positive aspect because it proves that 
the right and left hemibodies have a similar symmetric pattern, according to Table $\mathbf{1}$.

Table 1. Biophotogrammetric means and standard error of the following clinical conditions: Shoulder Elevation (SE), Scapula Rotation (SR), Trunk Inclination (TI) and Pelvic Inclination (PI), right and left sides, in road cyclists.

\begin{tabular}{|c|c|c|c|c|}
\hline Clinical Conditions & Sides & Mean & SE & \multirow{2}{*}{$\boldsymbol{P}$ Value } \\
\hline \hline \multirow{2}{*}{ SE } & Right Side & 98.56 & \pm 1.56 & \multirow{2}{*}{$0.45^{\mathrm{ns}}$} \\
\cline { 2 - 4 } & Left Side & 100.07 & \pm 1.22 & \\
\hline \multirow{2}{*}{ SR } & Right Side & 128.43 & \pm 3.35 & \multirow{2}{*}{$0.60^{\mathrm{ns}}$} \\
\cline { 2 - 4 } & Left Side & 126.28 & \pm 2.37 & \\
\hline \multirow{2}{*}{ TI } & Right Side & 114.00 & \pm 2.35 & \multirow{2}{*}{$0.76^{\mathrm{ns}}$} \\
\cline { 2 - 4 } & Left Side & 113.10 & \pm 1.87 & \\
\hline \multirow{2}{*}{ PI } & Right Side & 91.61 & \pm 1.03 & \multirow{2}{*}{$0.63^{\mathrm{ns}}$} \\
\cline { 2 - 4 } & Left Side & 92.29 & \pm 0.93 & \\
\hline
\end{tabular}

* Statistical significance at $\mathrm{p} \leq 0.05$.

${ }^{\text {ns }}$ Not significant

The analysis of the movements performed in both sitting and orthostatic positions suggest that there were no significant differences in the trunk flexion angle during the performance of the sporting gestures. However, when the triple maximum flexion of the lower limbs and the maximum extension of the lower limbs were analyzed, a statistical significance $(p<0.05)$ was found when the angles were compared in both positions (sitting and orthostatic), as shown in Table 2.

Table 2. Kinemetric means and standard error of the following clinical conditions: Trunk flexion (TF), Triple Maximum Flexion of the Lower Limbs (TMFLL) and Maximum Extension of the Lower Limbs (MELL) in standing (orthostatic) and sitting positions in road cyclists.

\begin{tabular}{|c|c|c|c|c|}
\hline Clinical Conditions & Position & Mean & SE & P Value \\
\hline \hline \multirow{2}{*}{ TF } & Sitting & 152.03 & \pm 1.98 & \multirow{2}{*}{$0.48^{\text {ns }}$} \\
\cline { 3 - 4 } & Orthostatic & 150.07 & \pm 1.95 & \\
\hline \multirow{2}{*}{ TMFLL } & $\begin{array}{c}\text { Sitting } \\
\text { Orthostatic }\end{array}$ & 88.04 & \pm 2.01 & \multirow{2}{*}{$0.00^{*}$} \\
\cline { 3 - 4 } & Sitting & 100.99 & \pm 1.76 & \\
\cline { 3 - 4 } MELL & \begin{tabular}{c} 
Orthostatic \\
\cline { 3 - 4 }
\end{tabular} & 173.48 & \pm 1.41 & $0.00^{*}$ \\
\hline
\end{tabular}

* Statistical significance at $\mathrm{p} \leq 0.05$.

${ }^{\text {ns }}$ Not significant.

In the present study, it was observed that the cyclists showed no impairment between the hemibodies, which is an important factor, considering that their body posture depends on the adjustments made during the performance of the sporting gestures. According to Cavanagh and Sanderson (1986) and Bertucci and Grappe (2009), cycling is an essentially symmetric sports activity in which the trunk and upper limb muscles also contribute to the pedaling, primarily when cyclists participate in competitions $[15,16]$. However, Daly and Cavanagh (1976) showed in their studies of recreational cyclists that the contribution of each lower limb was asymmetrical [17]. Gregor, Conconi and Broker (1991) reported that symmetry in pedaling technique is rare and that if the bike is not properly adjusted to the rider, it can accentuate asymmetry or cause injuries, anatomical discrepancies and neuromuscular deficit, thus making training more difficult [18].

Bolz and Davies (1984) reported that in individuals with lower limb discrepancies, the shorter lower limb is likely to exert less force [19]. Based on this assumption, it was hypothesized that in addition to the biomechanical changes that occur as a result of discrepancies, the longest limb should apply more force to the pedal, causing torque asymmetry and overload of the lower limb muscles, which leads to the development of tension in the ipsilateral lumbar/pelvic muscles. According to Cavanagh and Sanderson (1986), asymmetry during the propulsion phase generates an imbalance of muscle work, which may have a negative effect on the rider's performance compared with the condition in which the lower limbs contribute equally to generate power [15].

In the present study, the evaluation was only performed with right-handed individuals and showed that the angles evaluated did not show discrepancies between the hemibodies, which can be considered a relevant factor and indicative of a symmetrical pattern in the gestures evaluated. These changes can cause injuries and compromise the performance of the rider. For Carpes et al. (2004), the nondominant limb maintains the characteristic movement pattern compared with the dominant limb, when the dominant asymmetrical patterns are considered. Therefore, these findings reveal the need for a specific training practice with a focus on pedaling symmetry [20].

The computerized kinemetric assessment was aimed at the visual aspect of the angular patterns in two specific positions on the stationary bike: sitting and orthostatic. This assessment tool allows for understanding the biomechanics of the athletic gesture and posture during their standard performance.

Three posture angles were used in the study: Trunk flexion (TF), Triple Maximum Flexion of the Lower Limbs (TMFLL) and Maximum Extension of Lower Limbs (MELL). For the TMFLL axis-angle representation, it was noted that in the standing position there was a prevalence of the triple flexion of the lower limbs compared with the sitting position, which can interfere with an individual's torque for a more effective sporting gesture. Similarly, for the clinical condition of MELL, the lower limb extension threshold was higher in the standing position [21]. Therefore, the extension pattern is greater in the orthostatic position due to high body weight bearing compared with the sitting position, which is more effective in the short term, i.e., during the performance of the sports gestures, but increases muscle fatigue in the long term [22]. The results found for TMFLL and MELL were expected, though the body position and the bike adjustments should be carefully set for sports and recreation. The cyclists' positions on different types of bicycles used during competition generate changes in the lumbar spine, produce an inversion of the physiologic inter- 
vertebral angle and change the transmission of pressure to the spinal discs, compressing the front part of the disc, straining the back ligaments and causing lumbar pain [23, 24].

Cyclists constantly suffer from lumbar back pain [25]. Usabiaga et al. (1997) reported that an imbalance between the flexor and extensor muscles can cause low back pain in individuals with no fitness [23].

For the clinical condition of TF, it was observed that the trunk flexion had a similar pattern in both sitting and orthostatic positions due to the sports adaptation and training, thus reducing the relationship between body mass and aerodynamics.

Diefenthaeler et al. (2008) found that the trunk inclination angles did not present significant alteration on its sagittal movement. A larger trunk inclination was observed in the second quadrant of pedaling (from $90^{\circ}$ to $180^{\circ}$ of the crank cycle). However, the trunk flexion angle during the crank cycle presented an average value of $149^{\circ}\left( \pm 8^{\circ}\right)$ and a range of motion between $7^{\circ}$ and $11^{\circ}$ [26]. These findings corroborate our study, which found an average flexion value of $152^{\circ}$ in the sitting position and $150^{\circ}$ in the orthostatic position. The stability and control of trunk flexion at a certain angle is essential, as Mellion (1994) reported, because the lumbar spine is the support the rider uses to control and drive the bike and its firmness determines the comfort and quality in cycling [27]. For Usabiaga et al. (1997), the global mechanical load over the spine is reduced when the weight is supported by the upper limbs (aerodynamic position), which can be repeated by adjusting the seat height, which will project the rider's weight forward [23]. However, this forward bending position and prolonged compression to intervertebral discs can all be responsible for ongoing backache [28-30]. Groenendijk, Christiaans and Van Hulten (1992) have reported that more than 1 million members of the Dutch cycling population suffer from bike soreness [31]. Discomfort in specific body segments during the pedal stroke were also noted in the cyclists evaluated by Martins et al. (2006). Misalignment in the body positioning of cyclists classified as athletes (competitive) or non-athletes (recreational) may lead to discomfort, which results in injuries due to repetitive training [32].

\section{CONCLUSION}

Based on the results obtained, it can be concluded that the angle measurements found show that the biomechanics of the sports gestures in road cyclists was not compromised, nor was the angle specification between the hemibodies. This finding is directed in particular to the implementation and planning of training practices that will raise the awareness among cyclists of their bodies and the appropriate adjustments of the bicycle components. However, these bike adjustments with the corresponding body gestures of the cyclist are necessary to provide greater comfort, particularly to recreational cyclists who need to be well instructed by health professionals and physical trainers so that they can adapt, formulate and find the best angles and postures during their performance.

\section{CONFLICT OF INTEREST}

The authors confirm that this article content has no conflict of interest.

\section{ACKNOWLEDGEMENTS}

Declared none.

\section{REFERENCES}

[1] Mellion MB. Common cycling injuries, management and prevention. Sports Med 1991; 11: 52-70.

[2] Savelberg HHCM, Van De Port IGL, Willems PJB. Body configuration in cycling affects muscle recruitment and movement pattern. J Appl Biomech 2003; 19: 310-24.

[3] Hof AL. The force resulting from the action of mono- and biarticular muscles in a limb. J Biomech 2001; 34: 1085-9.

[4] Zajac FE. Understanding muscle coordination of the human leg with dynamical simulations. J Biomech 2002; 35: 1011-8.

[5] Yoshihuku Y, Herzog W. Maximal muscle power output in cycling: a modelling approach. J Sports Sci 1996; 14: 139-57.

[6] Diefenthaeler F, Bini, RR, Karolczak AP, Carpes FP. Ativação muscular durante a pedalada em diferentes posições do selim. Revista Brasileira de Cineantropometria e Desempenho Humano 2008; 10: 161-9.

[7] Martins EA, Dagnese F, Kleinpaul JF, Carpes FP, Mota CB. Avaliação do posicionamento corporal no ciclismo competitivo e recreacional. Revista Brasileira de Cineantro pometria e Desempenho Humano 2007; 9: 183-8.

[8] Herzog W, Zhang Y, Vaz MA, Guimarães ACS, Janssen C. Assessment of muscular fatigue using vibromyography. Muscle Nerve 1994; 17: 1156-61.

[9] Alencar TAM, Matias KFS, Oliveira FB. Kinesiology and biomechanics of cycling: A review. Revista Movimenta 2010; 3(1): 40-51.

[10] Wolf PR. Elements of photogrammetry. New York; Mac Graw Hill $1983 ; 626$.

[11] Mitchell HL, Newton I. Medical Photogrammetric Measurement: Overview and Prospects. ISPRS J Photogram Remote Sensing 2002; 56: 286-4.

[12] Iunes DH, Castro FA, Salgado HS, Moura IC, Oliveira AS, Grossi DB. Confiabilidade intra e inter-examinadores e repetibilidade da avaliação postural pela fotogrametria. Revista Brasileira de Fisioterapia 2005; 9: 327-34.

[13] Welbergen E, Clijsen LPVM. The influence of body position on maximal performance in cycling. Eur J Appl Physiol 1990; 61: $138-42$.

[14] Mestdagh KV. Personal perspective: in search of an optimum cycling posture. Appl Ergonom 1998; 29: 325-34

[15] Cavanagh PR, Sanderson DJ. The Biomechanics of Cycling: Studies of the Pedaling Mechanics of Elite Pursuit Riders. In: Burke ER. Science of Cycling. Champaign: Human Kinetics 1986; 91-122.

[16] Bertucci W, Grappe F. Biomécanique du pédalage. In: Grappe F. Cyclisme et optimisation de la performance: sciences et méthodologie de l'entraînement. $2^{\text {nd }}$ ed. De Boeck Université 2009; 195-208.

[17] Daly DJ, Cavanagh PR. Asymmetry in Bicycle Ergometer Pedalling. Med Sci Sports Exerc 1976; 8: 204-8.

[18] Gregor RJ, Broker JP, Ryan MM. The Biomechanics of Cycling. Exerc Sport Sci Rev 1991; 19: 127-69.

[19] Bolz S, Davies GJ. Leg length differences and correlation with total leg strength. J Orthop Sports Phys Ther 1984; 6: 123-9.

[20] Carpes FP. Produção de torque no ciclismo: análise da simetria na pedalada durante $40 \mathrm{~km}$ de ciclismo simulado. Monografia de Especialização Universidade Federal de Santa Maria 2004.

[21] Roy SH, Bonato P, Knaflitz M. EMG assessment of back muscle function during cycling lifting. J Electromyogr Kinesiol 1998; 8: 233-45.

[22] Takaishi T, Yasuda Y, Moritani T. Neuromuscular fatigue during prolongued pedaling exercise at different pedaling rates. Eur J Appl Physiol Occup Physiol 1994; 69: 154-8. 
[23] Usabiaga J, Crespo R, Iza I, Aramendi J, Terrados N, Poza JJ. Adaptation of the lumbar spine to different positions in bicycle racing. Spine 1997; 22: 1965-9.

[24] Asplund C, Webb C, Barkdull T. Neck and Back Pain in Bicycling. Curr Sports Med Rep 2005; 4: 271-4.

[25] Salai, M. et al. Effect of changing the saddle angle on the incidence of low back pain in recreational bicyclists. Br J Sports Med 1999; 33(6): 398-400.

[26] Diefenthaeler F, Bini RR, Nabinger E, Laitano O, Pivetta Carpes FP et al. Proposta Metodológica para a Avaliação da Técnica da Pedalada de Ciclistas: Estudo de Caso. Rev Bras Med Esporte 2008; $14: 155-8$.

[27] Mellion MB. Neck and back pain in bicycling. Clin Sports Med 1994; 13: 137-64.
[28] Hennemann SA, Schumacher W. Hérnia de disco lombar: revisão de conceitos atuais. Revista Brasileira de Ortopetia 1994; 29: 11526.

[29] Nachemson A. Back pain: delimiting the problem in the next millenium. Int J Law Psychiatry 1999; 22: 473-90.

[30] Adams MA, Bogduk N, Burton K, Dolan P. The biomechanics of back pain. Church Livingston, Edinburgh, UK 2002.

[31] Groenendijk MC, Christiaans HCCM, VAN Hulten CMJ. Sitting comfort on bicycles. In: Megaw ED, Ed. Contemporary Ergonomics. Taylor and Francis 1992; 551-7.

[32] Martins EA, Dagnese F, Kleinpaul JF, Mota CB, Carpes FP Principais erros no posicionamento de ciclistas de diferentes níveis de condicionamento. In: XXIX Simpósio Internacional em Ciências do Esporte. São Paulo: CELAFISCS 2006; 108.

(C) da Silva et al.; Licensee Bentham Open.

This is an open access article licensed under the terms of the Creative Commons Attribution Non-Commercial License (http://creativecommons.org/licenses/by-nc/3.0/) which permits unrestricted, non-commercial use, distribution and reproduction in any medium, provided the work is properly cited. 